\title{
Cuspal Movement related to Different Polymerization Protocols
}

\author{
${ }^{1}$ Máyra Andressa Rodrigues Valinhos Piccioni, ${ }^{2}$ Flares Baratto-Filho, ${ }^{3}$ Milton Carlos Kuga \\ ${ }^{4}$ Eduardo Christiano Caregnatto de Morais, ${ }^{5}$ Edson Alves Campos
}

\section{ABSTRACT}

Objective: The aim of this study to investigate the effects of different polymerization protocols on the cuspal movement in class II composite restorations.

Materials and methods: Human premolar teeth were prepared with class II cavities and then restored with composite and three-step and two-step etch-and-rinse adhesive systems under different curing techniques $(n=10)$. It was used a lightemitting-diode curing unit and the mode of polymerization were: standard (exposure for 40 seconds at $700 \mathrm{~mW} / \mathrm{cm}^{2}$ ), pulse-delay (initial exposure for 6 seconds at $350 \mathrm{~mW} / \mathrm{cm}^{2}$ followed by a resting period of 3 minutes and a final exposure of 37 seconds at $700 \mathrm{~mW} / \mathrm{cm}^{2}$ ) and soft-start curing (exposure 10 seconds at $350 \mathrm{~mW} / \mathrm{cm}^{2}$ and 35 seconds at 700 $\left.\mathrm{mW} / \mathrm{cm}^{2}\right)$. The cuspal distance $(\mu \mathrm{m})$ was measured before and after the restorative procedure and the difference was recorded as cuspal movement. The data were submitted to two-way ANOVA and Bonferroni test $(p<0.05)$.

Results: The type of adhesive system did not influenced the cuspal movement for all the curing methods. Standard protocol showed the highest values of cuspal movement and was statistically different from the pulse-delay and soft-start curing modes

Conclusion: Although the cuspal displacement was not completely avoided, alternative methods of photocuring should be considered to minimize the clinical consequences of composites contraction stress.

Keywords: Etch-and-rinse adhesive, Bonding technique, Polymerization, Cuspal movement.

How to cite this article: Piccioni MARV, Baratto-Filho F, Kuga MC, de Morais ECC, Campos EA. Cuspal Movement related to Different Polymerization Protocols. J Contemp Dent Pract 2014;15(1):26-28.

Source of support: Nil

Conflict of interest: None

\footnotetext{
${ }^{1,4} \mathrm{PhD}$ Student, ${ }^{2}$ Titular Professor, ${ }^{3,5}$ Assistant Professor

1,3,5 Department of Restorative Dentistry, São Paulo State University, Araraquara School of Dentistry, Araraquara, São Paulo, Brazil

${ }^{2,4}$ Department of Restorative Dentistry, Positivo University Curitiba, PR, Brazil
}

Corresponding Author: Máyra Andressa Rodrigues Valinhos Piccioni, PhD Student, Department of Restorative Dentistry São Paulo State University, Araraquara School of Dentistry 1680 Humaitá St, Zip Code: 14801-903, Araraquara, São Paulo, Brazil, e-mail: mayraandressa@ig.com.br

\section{INTRODUCTION}

Dental resin composites have found increasing use as substitutes for dental amalgam due to their superior esthetics accompanied with good physical and mechanical properties. ${ }^{1}$ Most clinical problems of posterior resin composite restorations can be related to the polymerization of the material. During the polymerization process, a volumetric contraction varying between 1.5 and $5 \%$ can be observed, which results in the development of internal stresses. ${ }^{2}$ Additionally, the shrinkage stress can be manifested as cuspal movement, enamel cracks, dentin postoperative sensitivity and/or marginal gap formation that may compromise synergism at the restoration - tooth interface. ${ }^{3}$ This may lead to bacterial microleakage and ultimately pulpal inflammation or necrosis and secondary caries. ${ }^{4}$

Different approaches have been recommended in order to prevent the problems inherent to polymerization contraction. One of them is decrease the irradiance of the light source or by using different photoactivation protocols as 'soft start', 'ramp', 'pulse activation' or 'two-step'. Soft-start technique involves the so-called step-curing, where a reduced intensity of curing light is used during the first part of the polymerization period. ${ }^{5}$ The pulse-delay light-curing approach is characterized by delayed photo-polymerization (3-5 mins) between the low and high irradiance processes in order to allow the resin composite to adapt along the walls of the preparation before reaching the maximum gelation phase. ${ }^{6}$

Studies $^{7-9,13}$ reported that modulated photoactivation regimes improve the quality of marginal integrity. However, some researchers ${ }^{5,10,12}$ did not find benefit from modulated photoactivation. Therefore, positive impacts of the modulated photoactivation protocols on the resin composite restorations have been in a standing debate. The aim of the study was to investigate the effects of different polymerization protocols on the cuspal movement in class II composite restorations.

\section{MATERIALS AND METHODS}

Sixty extracted human premolar teeth were used in this study. The teeth were stored in $0.1 \%$ thymol solution at $5^{\circ} \mathrm{C}$. All the restorative procedures were made under simulated dentinal hydrostatic pressure, employing a previously described protocol. ${ }^{4} \mathrm{~A} 1.5 \mathrm{~mm}$ diameter glass ball was fixed to each cusp 
vertex as reference points for intercuspal distance measurements. Each tooth was subjected to preparation of a large mesio-occlusal-distal (MOD) cavity, with the bucco-lingual width (BLW) of the approximal boxes of the cavity being prepared to two-thirds of the BLW of the tooth and the occlusal isthmus being prepared to half the BLW. The cavity depth at the occlusal isthmus was standardized $(3.0 \mathrm{~mm})$ and the cervical wall was located $1 \mathrm{~mm}$ above the amelocemental junction (ACJ) at the cervical aspect of the proximal boxes. The teeth showing pulpal exposure after the preparation were discarded. Facial and lingual walls of the cavity were prepared parallel. The initial distance between reference balls was measured with a digital micrometer (Mitutoyo, 293-561, Kanagawa, Japan) and recorded as 'initial distance'. ${ }^{4}$

The specimens were randomly divided into six groups and submitted to the bonding protocols using three-step etchand-rinse [Scotchbond Multi-Purpose (SMP) (3 M/ESPE, St Paul, MN, USA)] and two-step etch-and-rinse [SingleBond (SB) (3M/ESPE, St Paul, MN, USA)] adhesive system under different curing techniques $(\mathrm{n}=10)$. All the materials were applied in accordance with the manufacturer's guidelines. A light-emitting-diode curing unit (Elipar Free Light 2-3 M/ESPE, St Paul, MN, USA) was used and the modes of polymerization were the following: standard (exposure for 40 seconds at $700 \mathrm{~mW} / \mathrm{cm}^{2}$ ), pulse-delay (initial exposure for 6 seconds at $350 \mathrm{~mW} / \mathrm{cm}^{2}$ followed by a resting period of 3 minutes and a final exposure of 37 seconds at $700 \mathrm{~mW} /$ $\mathrm{cm}^{2}$ ) and soft-start curing (exposure 10 seconds at $350 \mathrm{~mW} /$ $\mathrm{cm}^{2}$ and 35 seconds at $700 \mathrm{~mW} / \mathrm{cm}^{2}$ ). The total energy was $28 \mathrm{~J} / \mathrm{cm}^{2}$ for all the groups.

The composite resin Z350 (3M ESPE, St Paul, MN, USA) was inserted in three oblique increments and each layer was light-cured for 40 seconds. After the polymerization of the last increment of composite, the distance between the glass balls was measured and recorded as 'final distance'. The cuspal movement was obtained by calculating the difference between 'final' and 'initial' measurements. The results were subjected to statistical analysis by two-way ANOVA and Bonferroni post-hoc comparison procedure test $(\mathrm{p}<0.05)$.

\section{RESULTS}

The results of cuspal movement are presented in Table 1. The type of adhesive system did not influence the cuspal movement for all the curing methods. Standard protocol (1) showed the highest values of cuspal movement and was statistically different from the pulse-delay (2) and soft-start light (3) curing modes.

\section{DISCUSSION}

In general, light-curing units with very high intensity are recommended, based on studies of curing depths and physical properties of the resin composites. ${ }^{10,12}$ However, one must also consider the possible negative effect of high intensity lights on contraction stress development. During the lightcuring procedure, resin composite is transformed from a viscous-plastic state to a rigid-elastic state. At the beginning of the polymerization, contraction of the composite is compensated by its viscous flow. Then, the viscous flow is reduced, and stresses are transferred to the tooth structures and bonding interface. This happens when the composite reaches its gel point. To reduce the stress, the resin composite should have enough time to flow, and relieve contraction forces. In this respect, it is understood that a variety of modulated photoactivation regimes decrease the polymerization rate and, consequently, the contraction stress. ${ }^{10-13}$

It is important to note that the transfer of stresses to the adhesive interface and tooth structure occurs only in the presence of adequate bond between resin/tooth. In this sense, and knowing the performance differences between adhesives, three and two-step etch-and-rinse adhesives were used. Adhesives usually present different monomers and organic solvents and the latter can affect the mechanical properties as modulus of elasticity. It has been observed that the use of adhesives with low modulus of elasticity allow to act as a 'stress breaker'. ${ }^{4}$ However, in this study, there was no difference between the two adhesive systems employed. So, it is not possible to extrapolate for all adhesive systems.

It has been demonstrated the reduction of polymerization contraction stress for dental composites by two-step light activation and that the use of a light with a higher power density may cause more rapid development of polymerization contraction. On the other hand, the use of lights with lower intensity may produce reduced rates of polymerization and allow more time for molecular rearrangements, decreasing the polymerization contraction stress. ${ }^{13}$ A previous study reported that the use of a low initial light intensity $\left(270 \mathrm{~mW} / \mathrm{cm}^{2}\right)$ for 10 seconds followed by high intensity

Table 1: Means of cuspal displacement $(\mu \mathrm{m})$ and standard deviation (SD) for the etch-and-rinse adhesives

\begin{tabular}{llll}
\hline & Standard & Pulse-delay & Soft-start \\
\hline SMP & $16.1( \pm 6.2)^{\mathrm{A}, \mathrm{a}}$ & $9.6( \pm 4.6)^{\mathrm{A}, \mathrm{b}}$ & $8.5( \pm 3.5)^{\mathrm{A}, \mathrm{b}}$ \\
SB & $17.4( \pm 3.7)^{\mathrm{A}, \mathrm{a}}$ & $7.3( \pm 3.9)^{\mathrm{A}, \mathrm{b}}$ & $10.6( \pm 5.5)^{\mathrm{A}, \mathrm{b}}$ \\
\hline
\end{tabular}

Within each line, different lower case letters mean statistically difference; within each column, capital letters mean statistically difference ( $p<0.05)$, SMP: Scotchbond Multi-Purpose; SB: SingleBond 
light $\left(600 \mathrm{~mW} / \mathrm{cm}^{2}\right)$ for 50 seconds provides the best adaptation of resin composite to cavity walls and possibly the least polymerization contraction stress. ${ }^{7}$ Additionally, another study observed that the two-step photoactivation protocol was preferable, since it resulted in a significantly lower cuspal deflection (11\% lower, compared to the continuous illumination). ${ }^{9}$ The findings of the present study are in agreement with studies aforementioned showing that application of light intensity of less than the maximum resulted in a reduction of cuspal movement.

It is interesting to note that there was no difference between pulse-delay and soft starting curing. So, the use of soft-starting curing seems to be more appropriate for special patients, children and old-aged for not requiring a resting period. Additionally, enamel cracks and marginal gap formation were not evaluated, meaning that the lower values of cuspal movement does not necessarily mean best results in terms of clinical behavior.

On the other hand, two-step curing of resin composites may result in polymers with increased susceptibility to the action of softening substances in food and beverage. ${ }^{5}$ It has been demonstrated that the predominant reason for the reduced shrinkage stress attained with soft-start or pulse curing had a modest decrease in final conversion. ${ }^{10}$ Nowadays, the use of high intensity lamps $\left(\geq 1200 \mathrm{~mW} / \mathrm{cm}^{2}\right)$ can eliminate this problem. ${ }^{14,15}$

\section{CONCLUSION}

This study revealed that the cuspal displacement was not completely avoided, when pulse-delay and soft-start protocols were employed. Further researches are required in which alternative methods of photocuring should be considered to minimize the clinical consequences of composites contraction stress.

\section{REFERENCES}

1. Sarret DC. Clinical challenges and the relevance of materials testing for posterior composite restorations. Dent Mater 2005; 21(1):9-20.
2. Ferracane JL. Developing a more complete understanding of stresses produced in dental composites during polymerization. Dent Mater 2005;21(1):36-42.

3. Fleming GJP, Khan S, Afzal O, Palin WM, Burke FJT. Investigation of polymerisation shrinkage strain, associated cuspal movement and microleakage of MOD cavities restored incrementally with resin-based composite using an LED light curing unit. J Dent 2007;35(2):97-103.

4. Campos EA, Andrade MF, Porto-Neto ST, Campos LA, Saad JRC, Deliberador TM, Oliveira OB Jr. Cuspal movement related to different bonding techniques using etch-and-rinse and self-etch adhesive systems. Eur J Dent 2009;3(3):213-218.

5. Asmussen E, Peutzfeldt A. Two-step curing: influence on conversion and softening of a dental polymer. Dent Mater 2003; 19(6):466-470.

6. Feitosa VP, et al. Effects of different photo-polymerization protocols on resin-dentine $\mu \mathrm{TBS}$, mechanical properties and cross-link density of a nano-filled resin composite. J Dent 2012; 40(10):802-809.

7. Yoshikawa TBMF, Tagami J. A light-curing method for improving marginal sealing and cavity wall adaptation of resin composite restorations. Dent Mater 2001;17(4):359-366.

8. Mehl A, Hickel R, Kunzelman KH. Physical properties and gap formation of light-cured composites with and without 'softstart' polymerization. J Dent 1997;25(3-4):321-330.

9. Blažić L, Pantelić D, Savić-Šević S, Murić B, Belić I, Panić B. Modulated photoactivation of composite restoration: measurement of cuspal movement using holographic interferometry. Lasers Med Sci 2011;26(2):179-186.

10. Lu H, Stansbury JW, Bowman CN. Impact of curing protocol on conversion and shrinkage stress. J Dent Res 2005;84(9):822-826.

11. Soh MS, Yap AU. Influence of curing modes on crosslink density in polymer structures. J Dent 2004;32(4):321-326.

12. Friedl KH, Schmalz G, Hiller KA, Markl A. Marginal adaptation of class V restorations with and without 'soft-start' polymerization. Oper Dent 2000;25(1):26-32.

13. Lim BS, Ferracane JL, Sakaguchi RL, Condon JR. Reduction of polymerization contraction stress for dental composites by two-step light activation. Dent Mater 2002;18(6):436-444.

14. Brandt WC, Lacerda RF, Souza-Junior EJ, Sinhoreti MA. Effect of photoactivation mode on the hardness and bond strength of methacrylate- and silorane monomer-based composites. J Adhes Dent 2013;15(1):33-39.

15. Calixto LR, Tonetto MR, Pinto SCS, Barros ED, Borges AH, Lima FVP, Andrade MF, Bandéca MC. Degree of conversion and hardness of two different systems of the Vitrebond ${ }^{\mathrm{TM}}$ Glass Ionomer Cement Light Cured with Blue LED. J Contemp Dent Pract 2013;14(2):244-249. 